\title{
New journals for publishing medical case reportsEC
}

\author{
Katherine G. Akers, PhD \\ See end of article for author's affiliation. \\ DOI: http://dx.doi.org/10.3163/1536-5050.104.2.010
}

\begin{abstract}
Because they do not rank highly in the hierarchy of evidence and are not frequently cited, case reports describing the clinical circumstances of single patients are seldom published by medical journals. However, many clinicians argue that case reports have significant educational value, advance medical knowledge, and complement evidence-based medicine. Over the last several years, a vast number $(\sim 160)$ of new peer-reviewed journals have emerged that focus on publishing case reports. These journals are typically open access and have relatively high acceptance rates. However, approximately half of the publishers of case reports journals engage in questionable or "predatory" publishing practices. Authors of case reports may benefit from greater awareness of these new publication venues as well as an ability to discriminate between reputable and non-reputable journal publishers.
\end{abstract}

Keywords: Medical Records; Publishing; Access to Information; Periodicals as Topic; Editorial Policies; Evidence-Based Medicine; Education, Medical

Case reports - which are detailed descriptions of the symptoms, diagnoses, disease courses, and treatments of one or a few patients-are a prominent form of medical communication that can be traced back to ancient Egypt [1]. Starting in the late 1970s, however, case reports became viewed as less scientific than research articles, and the movement toward evidence-based medicine in the late 1980s pushed case reports down to the bottom of the hierarchy of evidence [2]. Also, case reports do not receive nearly as many citations as meta-analyses or randomized controlled trials [3]. In part for these reasons, many journals have ceased to publish case reports or have severely limited the number of case reports published per issue, thereby suppressing this type of publication.

Over the last couple of decades, much debate has centered on the value of case reports [4]. Whereas some view case reports as mere anecdotes that can cause more harm than good by highlighting rare occurrences $[5,6]$, others believe that case reports are important for medical progress [7, 8]. Whereas randomized controlled trials can provide strong

Supplemental Table 1 is available with the online version of this journal. confirmatory evidence of treatment efficacy, case reports serve different purposes: communicating the discovery of new diseases, disease mechanisms, or therapeutic approaches; alerting the medical community to adverse or beneficial effects of drugs; and generating new hypotheses to be tested by studies that employ more scientifically rigorous research designs $[9,10]$.

Beyond being a mere bystander of evidence-based medicine, case reports can serve as sources of evidence in systematic reviews and meta-analyses [11], and a new type of "evidence-based case report" demonstrates how to apply knowledge gleaned from clinical trials and systematic reviews to the management of individual patients [12]. A particular observation independently reported by several different case reports can be considered a "nugget" of information calling attention to reliable and potentially influential findings [13]. Case reports possess considerable educational value, not only giving readers a chance to confront novel clinical scenarios and reflect upon their own practice [14], but also training authors to think and write clearly and critically [15]. Furthermore, case studies have the potential to be highly read and to have a significant impact on subsequent clinical research [16, 17]. 


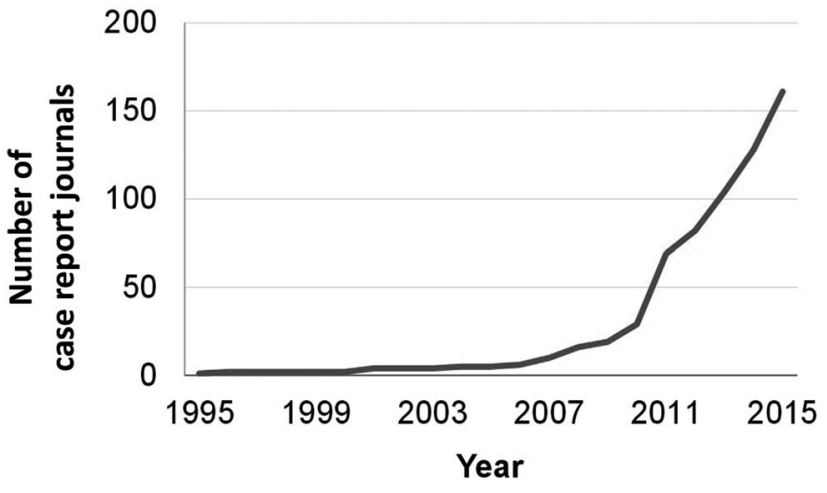

Figure 1

Rapidly increasing number of new journals that focus on publishing medical case reports

\section{RAPID EMERGENCE OF NEW CASE REPORTS JOURNALS}

Although temporarily shadowed by the rise of evidence-based medicine, case reports are once again being recognized as valuable contributions to the medical literature. At the same time, clinical faculty and residents are facing increased pressure to publish $[18,19]$, and writing a case report is a relatively quick and easy way to engage in scholarship. To meet a growing demand for venues in which to publish case reports, new peer-reviewed journals that focus-sometimes exclusively-on publishing case reports have rapidly emerged over the last several years (Figure 1). As of mid-2015, at least 160 case reports journals from 78 publishers are in existence (Table 1, online only), with more launching each month. Some of these journals are general medical journals (e.g., BioMed Central's Journal of Medical Case Reports, BMJ Publishing Group's BMJ Case Reports, Wiley's Clinical Case Reports), and others serve specific branches of medicine (e.g., Elsevier's Epilepsy and Behavior Case Reports and Gynecologic Oncology Reports, Oxford University Press's Journal of Surgical Case Reports). Some have been introduced as "sister journals" or "companion journals" to more established titles (e.g., Elsevier's JAAD Case Reports is a companion to the Journal of the American Academy of Dermatology; De Gruyter's Case Reports in Perinatal Medicine is a companion to the Journal of Perinatal Medicine).

So far, nearly half of these case report journals (41\%) have been indexed in PubMed (Table 1, online only), which facilitates the discovery of case reports by researchers and clinicians and increases their prospects of influencing medical research or practice.
Only 1 title has received a Thomson Reutersassigned journal impact factor (Taylor \& Francis' Neurocase, with an impact factor of 1.124). Although additional case reports journals may eventually receive impact factors, it is expected that their impact factors will be rather low due to the infrequency with which case reports are cited [3].

Unlike mainstream medical journals that publish only those case reports describing the most unique and striking clinical situations, these new journals accept case reports highlighting a wide range of clinical issues (e.g., observations that shed new light on disease pathogenesis, previously unreported adverse effects of drugs or other treatments, demonstrations of new therapeutic approaches, ethical challenges in patient management, strategies for preventing or overcoming medical errors) as long as they add to the corpus of medical knowledge and convey an important educational message $[20,21]$. Thus, whereas mainstream medical journals may have a case report acceptance rate of only $5 \%$ [22], case report journals generally have a higher acceptance rate, ranging between $20 \%$ and $70 \%$.

The vast majority of case report journals (94\%) are open access (Table 1, online only), meaning that their contents are available online for anyone to read without a subscription. As such, they usually require authors to pay an article processing fee upon acceptance, typically between $\$ 300$ and $\$ 1,200$. A much smaller number of case reports journals are subscription-based, with some providing an open access option for a fee. BMJ Case Reports employs a unique funding model; in exchange for a \$297 annual fellowship fee, individuals can access the contents of the journal and submit an unlimited number of case reports in a 12-month period. One of the advantages of online, open-access journals is quick publication, and many case reports journals advertise an acceptance-to-publication delay of one month or less.

\section{AUTHORS BEWARE: CASE REPORTS JOURNALS WITH QUESTIONABLE PUBLISHING PRACTICES}

An unfortunate outcome of the open access publishing movement is the growth of "predatory" journals that exploit the author-pays model [23, 24], which is a particular problem in the biomedical domain [25]. These journals primarily exist to collect article processing charges without providing much value in return, such as solid peer review, 
professional editing and typesetting, preservation of journal contents, or indexing in major article databases. The practice of predatory publishing is rampant among case report journals. Specifically, a shocking $50 \%$ of publishers of case report journals (accounting for 49 out of 160 journal titles) engage in questionable publishing practices (Table 1, online only). These publishers are either listed on Jeffrey Beall's list of potential, possible, or probable predatory scholarly open-access publishers [26] or otherwise exhibit suspect behavior, such as not being transparent about publisher identity and location, boasting an "unofficial" or bogus journal impact factor [27], or falsely claiming to be indexed in PubMed. Therefore, when choosing a journal in which to publish a case report, authors should take care to avoid journals that display predatory warning signs, such as sending spam email solicitations for submissions or editorial board memberships, promising acceptance decisions within a time period that is too short for careful peer review, lacking a named editor-in-chief with academic credentials, having a website riddled with grammatical errors and broken links, and publishing articles that have not been professionally typeset [27, 28].

\section{CONCLUSIONS}

The emergence of new peer-reviewed journals focusing on publishing case reports offers greater opportunities for clinical faculty, fellows, and residents to make scholarly contributions to medicine. With relatively high acceptance rates, clinicians stand a good chance of getting their case reports published, especially if they write case reports that tell a good story, are well-informed, and convey a clear and useful educational message [2933]. Many case reports journals are produced by reputable publishers and are indexed in PubMed, providing some assurance of their quality.

However, this new genre of case reports journals is rife with questionable publishing practices, leaving authors vulnerable to publishing a case reportsometimes at a steep cost - that undergoes inferior peer review and that could disappear without warning due to unstable business practices. Clinician-scholars and librarians who provide publishing support could benefit from an increased awareness of these new case report publication venues and the ability to recognize the warning signs of predatory publishers.

\section{REFERENCES}

1. Nissen T, Wynn R. The history of the case report: a selective review. J R Soc Med. 2014 Mar 12;5(4):1-5.

2. Nissen T, Wynn R. The recent history of the clinical case report: a narrative review. JRSM Short Reports. 2012;3:87. 3. Patsopoulos NA, Analatos AA, Ioannidis JPA. Relative citation impact of various study designs in the health sciences. JAMA. 2005 May 18;293(19):2362-6.

4. Nissen T, Wynn R. The clinical case report: a review of its merits and limitations. BMC Res Notes. 2014;7:264.

5. Hoffman JR. Rethinking case reports: highlighting the extremely unusual can do more harm than good. WJM. 1999;170:253-4.

6. McGee G. The plural of anecdote is not Ambien. Scientist Magazine. 1 Oct 2006.

7. Vandenbroucke JP. In defense of case reports and case series. Ann Intern Med. 2001 Feb 20;134(4):330-4.

8. Smith R. Why do we need Cases Journal? Cases J. 2008; $1: 1$.

9. Vandenbroucke JP. Case reports in an evidence-based world. J R Soc Med. 1999 Apr;92(4):159-63.

10. Arnaiz JA, Carne X, Riba N, Codina C, Ribas J, Trilla A. The use of evidence in pharmacovigilance: case reports as the reference source for drug withdrawals. Eur J Clin Pharmacol. 2001 Apr;57(1):89-91.

11. Jenicek M. Clinical case reporting in evidence-based medicine. 2nd ed. London, UK: Arnold Publishers; 2001. 12. Godlee F. Applying research evidence to individual patients. BMJ. 1998 May 30;316(7145):1621-2.

13. Smalheiser NR, Shao W, Yu PS. Nuggets: findings shared in multiple clinical case reports. J Med Libr Assoc. 2015 Oct;103(4):171-6. DOI: http://dx.doi.org/10.3163/ 1536-5050.103.4.002.

14. Caban-Martinez A, Garcia-Beltran WF. Advancing medicine one research note at a time: the educational value in clinical case reports. BMC Research Notes. 2012 Jul 6;5:293.

15. Bhattacharrya S, Miller J, Ropper AH. The case for case reports. Ann Neurol. 2014 Oct;76(4):484-6.

16. Mahajan RP, Hunter JM. Case reports: should they be confined to the dustbin? Br J Anaesthesia. 2008 Jun;100(6): 744-6.

17. Albrecht J, Meves A, Bigby M. Case reports and case series from Lancet had significant impact on medical

literature. J Clinical Epidemiology. 2005 Dec;58(12):122732.

18. Tijdink JK, Vergouwen ACM, Smulders YM.

Publication pressure and burn out among Dutch medical professors: a nationwide study. PLOS ONE. 2013 Sep 4; 8(9):e73381.

19. Yuan HF, Xu WD, Hu HY. Young Chinese doctors and the pressure of publication. Lancet. 2013 Feb 2;381(9864): e4. 
20. Kidd M, Hubbard C. Introducing Journal of Medical Case Reports. J Med Case Rep. 2007 Feb 2;1:1.

21. Agha R, Rosin RD. Time for a new approach to case reports. Int J Surg Case Rep. 2010;1(1):1-3.

22. Moss P. Whither the case report? J Infect. 2008;57:93-4. 23. Beall J. Predatory publishers are corrupting open access. Nature. 2012 Sep 13;489(7415):179.

24. Butler D. Investigating journals: the dark side of publishing. Nature. 2013 Mar 28;495(7442):433-5.

25. Beall J. Medical publishing triage-chronicling predatory open access publishers. Ann Med Surgery. 2013 Jun 22;2(2):47-9.

26. Beall J. List of publishers: Beall's list [Internet]. Scholarly Open Access [28 Dec 2015; cited 29 Dec 2015]. $<$ http://scholarlyoa.com/publishers/>.

27. Gutierrez FRS, Beall J, Forero DA. Spurious alternative impact factors: the scale of the problem from an academic perspective. Bioessays. 2015 May;37(5):4746.

28. Mehrpour S, Khajavi Y. How to spot fake open access journals. Learned Publishing. 2014 Oct;27(4):269-74.

29. Wright SM, Kouroukis C. Capturing zebras: what to do with a reportable case. CMAJ. 2000 Aug 22;163(4):429_ 31 .
30. Chelvarajah R, Bycroft J. Writing and publishing case reports: the road to success. Acta Neurochirurgica. 2004 Mar;146(3):313-6.

31. Green BN, Johnson CD. How to write a case report for publication. J Chiropr Med. 2006 Summer;5(2):72-82.

32. Bayoumi AM, Kopplin PA. The storied case report. CMAJ. 2004 Sep 14;171(6):569-70.

33. Rison RA. A guide to writing case reports for the Journal of Medical Case Reports and BioMed Central Research Notes. J Med Case Rep. 2013 Nov 27;7:239.

\section{AUTHOR'S AFFILIATION}

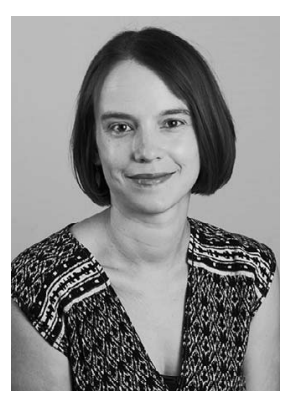

Katherine G. Akers, PhD, katherine.akers@wayne.edu, Biomedical Research and Data Specialist, Shiffman Medical Library, Wayne State University, 320 East Canfield Street, Detroit, MI 48201

Received September 2015; accepted October 2015 